\title{
NaOH Pretreatment of Wheat Straw at a Mesophilic Temperature: Effect on Hydrolysis and Loss of Organic Carbon
}

\author{
Hao Jiang, Yong Zeng, Hong Nie, Yeqing Li, Jiangtao Ding, Hongjun Zhou* \\ Institute of New Energy, State Key Laboratory of Heavy Oil Processing, \\ Beijing Key Laboratory of Biogas Upgrading Utilization, China University of Petroleum, \\ Beijing 102249, China
}

Received: 24 February 2016

Accepted: 12 April 2016

\begin{abstract}
A common approach to increasing biogas production is enhancing the hydrolysis of wheat straw by removing the lignin-using chemicals. However, partial organic matter will also dissolve into chemical solutions during pretreatment, which leads to the loss of organic matter for the anaerobic digestion process. The enzymatic hydrolysis of wheat straw and loss of total organic carbon increased with $\mathrm{NaOH}$ concentration and pretreatment time. The results suggest that when evaluating a pretreatment method, not just the hydrolysis but the loss of organic matter should be taken into consideration.
\end{abstract}

Keywords: $\mathrm{NaOH}$ pretreatment, lignin, cellulase, total organic carbon (TOC), biogas

\section{Introduction}

Lignocellulosic biomass has been regarded as an abundantly available resource to produce bioenergy and other biochemical products [1-2] since it is rich in carbohydrate polymers that can be decomposed into hexose and pentose sugars. Wheat straw is one kind of the largest lignocellulosic agricultural byproducts and its annual output throughout the world is estimated at about 850 million tons [3-4]. The traditional utilization (animal feed, agricultural fertilizer, rural solid-fuel, etc.) cannot consume wheat straw completely and the residue is a big challenge for the environment and public health [5]. In recent decades, anaerobic digestion (AD) of wheat straw to produce biogas has been studied both in

*e-mail: zhouhongjun@cup.edu.cn the lab and on industrial scales, whereas effective and economical pretreatments are still required to improve the digestibility of wheat straw. Without pretreatment, the cellulosic biomass would be much more difficult to hydrolyze completely, resulting in a poor biogas yield and long fermentation period.

A wide variety of methods (e.g., bases, acids, high temperature, milling, steam explosion, catalyzed hydrolyses, and their combination) have been used to pretreat straw to increase its biodegradability [6-7]. Among them, alkaline pretreatment is regarded as one of the most efficient methods and sodium hydroxide $(\mathrm{NaOH})$ is widely used for its outstanding delignification capacity and simple operation [8-9]. Carrillo et al. [10] indicated that the hydrolysis degree of wheat straw pretreated by $\mathrm{NaOH}$ was more than three times that compared with untreated wheat straw. Taherdanak et al.[11] also found that the lignin and hemicellulose in wheat plants were 
reduced using $8 \%$ (wt) $\mathrm{NaOH}$ for pretreatment, while the highest yield of methane production and glucose content were obtained by pretreatment at $75^{\circ} \mathrm{C}$ for $60 \mathrm{~min}$.

$\mathrm{NaOH}$ pretreatment was proved effective in treating biomass, particularly for lignocellulose [12]. It may cause lignocellulose to change in both chemical property and physical structure, for instance, swell leading to an increase in the internal surface area, a decrease in the degree of polymerization and crystallinity, separation of structural linkages between lignin and carbohydrates, and disruption of the lignin structure [13-14]. These changes will release a mass of organic matter (lipid, monose, and other carbohydrates) into liquid. On the one hand, $\mathrm{NaOH}$ pretreatment can enhance hydrolysis of substrates and improve yield of sugar [15]. But on the other hand, a lot of low molecular weight organic matter that is easily available for microorganisms will be wasted and may pollute the environment [16].

Organic carbon is an important carbon resource for microorganisms in $\mathrm{AD}$ [17-18]. As a consequence, to evaluate a pretreatment method, not only the yield of sugar or rate of hydrolysis should be taken into consideration, but the loss of organic matters should be given greater importance.

This study investigated the effects of $\mathrm{NaOH}$ pretreatment on wheat straw at a mesophilic temperature. The hydrolysis of pretreated wheat straw by different $\mathrm{NaOH}$ concentrations and raw material were compared. The changes in composition and structure of the pretreated wheat straw were also detected. Finally, the losses of total organic carbon in different pretreatment conditions were presented and compared.

\section{Materials and Methods}

\section{Wheat Straw}

The wheat straw was collected from a farm in Henan province, China. After collection, it was cut into $2 \mathrm{~cm}$ and washed twice with purified water to remove soil and dust. Afterward it was dried at $70^{\circ} \mathrm{C}$ to constant weight and stored at $3^{\circ} \mathrm{C}$ to keep raw material fresh according to the previous report [19]. The basic compositions of raw wheat straw are given in Table 1.

Table1. Compositions of raw material.

\begin{tabular}{|c|c|c|}
\hline Constituent & Unit & Mean \pm SD \\
\hline TS & \%FM ${ }^{*}$ & $94.7 \pm 1.4$ \\
\hline VS & \%TS & $95.3 \pm 2.1$ \\
\hline Hemicellulose & \%TS & $23.1 \pm 2.2$ \\
\hline Cellulose & \%TS & $34.1 \pm 2.7$ \\
\hline Lignin & \%TS & $16.7 \pm 1.8$ \\
\hline Ash & \%TS & $4.4 \pm 1.1$ \\
\hline
\end{tabular}

*FM: fresh matter

\section{Sodium Hydroxide Pretreatment}

The pretreatments of wheat straw using $\mathrm{NaOH}$ were carried out in bottles with a total volume of 3 L. Firstly, $65 \mathrm{~g}$ of wheat straw was added into each bottle. And then 1.5 $\mathrm{L} \mathrm{NaOH}$ solution with concentrations of $0 \%, 4 \%, 6 \%$, and $8 \%(w t)$ was added to each bottle. The bottles were kept in an incubator (Hadonglian, China) at $35^{\circ} \mathrm{C}$. During the pretreatment, $4 \mathrm{~g}$ substrate was taken from each bottle for analysis after two, five, and eight days.

\section{Enzymatic Digestion Of Wheat Straw}

Enzymatic digestion was performed according to previous reports [20-21]. Raw material and pretreated wheat straw were milled into 40 meshes and then sealed in a bag with bore diameter smaller than 80 meshes so that the products of hydrolysis could pass through the bag and the residual wheat straw would be left in it. Then $0.2 \mathrm{~g}$ wheat straw and $4 \mathrm{ml}$ enzyme cocktail (15FPU/g wheat straw) dissolved in $16 \mathrm{ml}$ acetate buffer $(\mathrm{pH} 4.7)$ were put into a $50 \mathrm{ml}$ erlenmeyer flask. Then all the erlenmeyer flasks were sealed and incubated at $45^{\circ} \mathrm{C}$ and $120 \mathrm{rpm}$ for 8,24 , and $48 \mathrm{~h}$. Each enzymatic hydrolysis assay was performed in triplicate. Enzymatic digestion rate was calculated as in Eq. (1) [20]:

$$
\text { Enzymatic digestion }(\%)=\left[\mathrm{m}_{1}-\left(\mathrm{m}_{2} \times \mathrm{c}\right)\right] / \mathrm{m}
$$

...where $m$ is the dry weight of substrate, $m_{1}$ is the total weight of substrate and the bag, $m_{2}$ is the total weight of remaining substrate and bag, and $\mathrm{c}$ is the correction coefficient of the bag (weight ratio of the bag before hydrolysis to the bag after hydrolysis).

\section{Substrate Analysis}

Total solids (TS) and volatile solids (VS) were determined according to standard methods [22]. Neutral detergent fiber (NDF), acid detergent fiber (ADF), and acid detergent lignin (ADL) were measured by a fiber analyzer (200I, ANKOM, USA) according to procedures supplied by ANKOM Technology [23]. After analyzing $\mathrm{ADL}$, samples were ignited at $550^{\circ} \mathrm{C}$ for $4 \mathrm{~h}$ in a muffle oven to get the ash. Hemicellulose, cellulose, and lignin were calculated according to Eqs. (2), (3), and (4):

$$
\begin{gathered}
\text { Hemicellulose }(\%)=\text { NDF }(\%)-A D F(\%) \\
\text { Cellulose }(\%)=\text { ADF }(\%)-A D L ~(\%) \\
\text { Lignin }(\%)=\text { ADL }(\%)-A s h(\%)
\end{gathered}
$$

\section{Microscope Observation}

A scanning electron microscope (SEM, S-4800, Hitachi, Japan) was used to visualize the surficial differences between untreated and pretreated wheat straw 
at a magnification of $500 \times$. The wheat straw was metalized with a thin layer of gold in a sputter coater polaron (E1045, Hitachi, Japan) to ensure the conductivity of its observation.

\section{FTIR Observation}

Fourier transform infrared spectroscopy (FTIR) spectra was obtained by a Nicolet iS10 FTIR spectrophotometer (Thermo Fisher Scientific, USA). Each spectrum was obtained with an average of two scans and a resolution of $4 \mathrm{~cm}^{-1}$, from 500 to $4,000 \mathrm{~cm}^{-1}$ [11].

\section{TOC Analysis}

Total organic carbon (TOC) was measured by a DR6000 spectrophotometer (Hach, USA). The liquid remaining in each bottle was collected and centrifuged at 10,000 rpm for $10 \mathrm{~min}$ (HC-2066, ZONKIA, China), and the supernatant was analyzed. According to a TOC test method provided by the Hach Company [24], the standard agents were added into the diluted sample successively, and then the sample was digested at $102^{\circ} \mathrm{C}$ for $2 \mathrm{~h}$. After cooling to room temperature, the sample was measured at $430 \mathrm{~nm}$. The loss ratio of TOC was calculated according to Eq. (5):

$$
\text { Loss ratio of TOC }(\%)=\mathrm{V} \times \mathrm{c} / \mathrm{m}
$$

...where $c$ is the concentration of TOC $(\mathrm{g} / \mathrm{L}), V$ is the volume of liquid phase in $\mathrm{L}$, and $m(\mathrm{~g})$ is the dry weight of the substrate.

\section{Results and Discussion}

\section{The Influence of $\mathrm{NaOH}$-pretreatment on Hydrolysis of Wheat Straw}

In order to understand the effects of $\mathrm{NaOH}$ pretreatment on wheat straw, the compositions, including hemicellulose, cellulose, and lignin (as well as ash) of wheat straw before and after pretreatment were tested. TS and VS of wheat straw pretreated by different concentrations of $\mathrm{NaOH}$ for 2, 5, and 8 days were compared. On the whole, as listed in Table 2, TS and VS were reduced with the increase of pretreatment time and $\mathrm{NaOH}$ concentration.

The raw wheat straw containing $23.1 \%$ hemicellulose, $34.1 \%$ cellulose, $16.7 \%$ lignin, and $4.4 \%$ ash (Table 1 ) was similar to other reports [25-26]. As shown in Fig. 1, after pretreatment the cellulose and hemicellulose had a small reduction comparing to the untreated straw. With the increase of $\mathrm{NaOH}$ concentration and pretreatment time, the contents of cellulose and hemicellulose decreased slowly. The maximum losses of cellulose and hemicellulose were received when using $8 \% \mathrm{NaOH}$ to treat for eight days, which were $41.2 \%$ and $51.1 \%$, respectively, on the basis of contents in raw wheat straw. While for lignin, the loss was
Table 2. Comparison of TS and VS of wheat straw pretreated by different $\mathrm{NaOH}$ concentration and time.

\begin{tabular}{|c|c|c|c|}
\hline $\begin{array}{c}\text { Pretreatment } \\
\text { time }\end{array}$ & $\begin{array}{c}\text { Concentration of } \\
\mathrm{NaOH}(\mathrm{wt})\end{array}$ & $\mathrm{TS}(\% \mathrm{FM})$ & $\mathrm{VS}(\% \mathrm{TS})$ \\
\hline \multirow{4}{*}{2 days } & $0 \%$ & $93.4 \pm 4.8$ & $92.3 \pm 5.6$ \\
\cline { 2 - 4 } & $4 \%$ & $92.7 \pm 7.3$ & $95.1 \pm 2.2$ \\
\cline { 2 - 4 } & $6 \%$ & $\begin{array}{c}89.2 \pm \\
12.9\end{array}$ & $94.4 \pm 2.7$ \\
\cline { 2 - 4 } & $8 \%$ & $90.5 \pm 5.3$ & $89.9 \pm 4.7$ \\
\hline \multirow{4}{*}{5 days } & $0 \%$ & $87.2 \pm 4.1$ & $93.5 \pm 1.1$ \\
\cline { 2 - 4 } & $4 \%$ & $90.6 \pm 6.7$ & $92.7 \pm 4.8$ \\
\cline { 2 - 4 } & $6 \%$ & $84.3 \pm 0.9$ & $93.6 \pm 3.1$ \\
\hline \multirow{5}{*}{8 days } & $0 \%$ & $82.5 \pm 4.8$ & $91.4 \pm 6.2$ \\
\cline { 2 - 4 } & $4 \%$ & $81.1 \pm 1.2$ & $93.1 \pm 4.8$ \\
\cline { 2 - 4 } & $6 \%$ & $82.4 \pm 3.3$ & $90.8 \pm 1.7$ \\
\cline { 2 - 4 } & $8 \%$ & $78.6 \pm 3.5$ & $88.3 \pm 6.7$ \\
\hline
\end{tabular}

greatly caused once $\mathrm{NaOH}$ was added, and the maximum was $77.2 \%$ when $6 \% \mathrm{NaOH}$ was used to treat for five days. These changes indicated that $\mathrm{NaOH}$ pretreatment affected the physical structure and chemical properties of wheat straw.

Lignin is thought to be one of the strongest resistance materials for enzymes and microorganisms during anaerobic digestion. The results above proved that, compared with raw material, $\mathrm{NaOH}$ pretreatment of wheat straw at a mesophilic temperature could reduce lignin significantly, but when the $\mathrm{NaOH}$ concentration and pretreatment time increased, there was no obvious enhancement of this effect. So the pretreatment conditions should be optimized in order to keep cellulose and hemicellulose and decrease lignin, as well as to reduce the treatment cost and environmental impact.

The Influence of $\mathrm{NaOH}$-pretreatment on Physicochemical Structure of Wheat Straw

After $\mathrm{NaOH}$-pretreatment for eight days, SEM was used to identify the structural changes of wheat straw (Fig. 2). The surface of wheat straw without pretreatment was very smooth and all the microfibers and hemicelluloses were not visible (Fig. 2a). After pretreatment, the surface of wheat straw became coarse and microfiber could be observed (Figs 2b-2d). NaOH-pretreatment could effectively disrupt the structure of wheat straw.

FTIR was used to analyze the changes in functional groups of lignocelluloses and the details are shown in Fig. 3.

Some distinct bands from the pretreated wheat straw revealed shifts compared to those from raw wheat straw, implying that there were some changes in the chemical structure. The spectra of pretreated wheat 

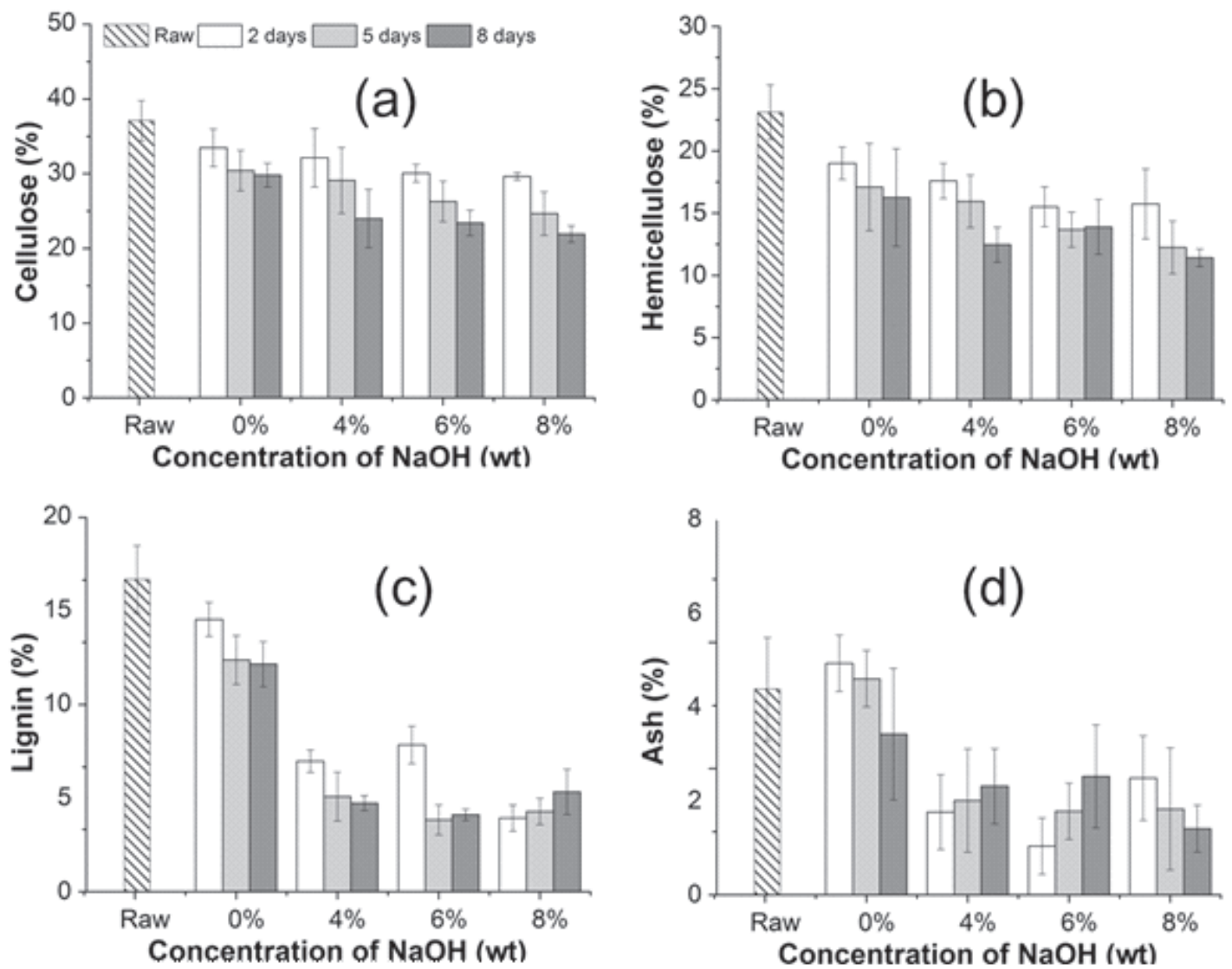

Fig. 1. Time course of chemical composition of wheat straw treated at different concentration of $\mathrm{NaOH}$. Changes of cellulose a), hemicellulose b), lignin c) and ash d) in wheat straw at different pretreatment conditions. Composition is on the basis of dry matter of raw wheat straw. The legend in a) applies to b), c) and d).

straw can be distinguished by inspecting the peak at $1,731-1,733 \mathrm{~cm}^{-1}$ region, which corresponds to ester linkages of hemicellulose [27]. It is obvious that the transmittance of pretreated wheat straw at $1,732 \mathrm{~cm}^{-1}$ is higher than that of raw wheat straw, which indicates that some hemicellulose was removed after

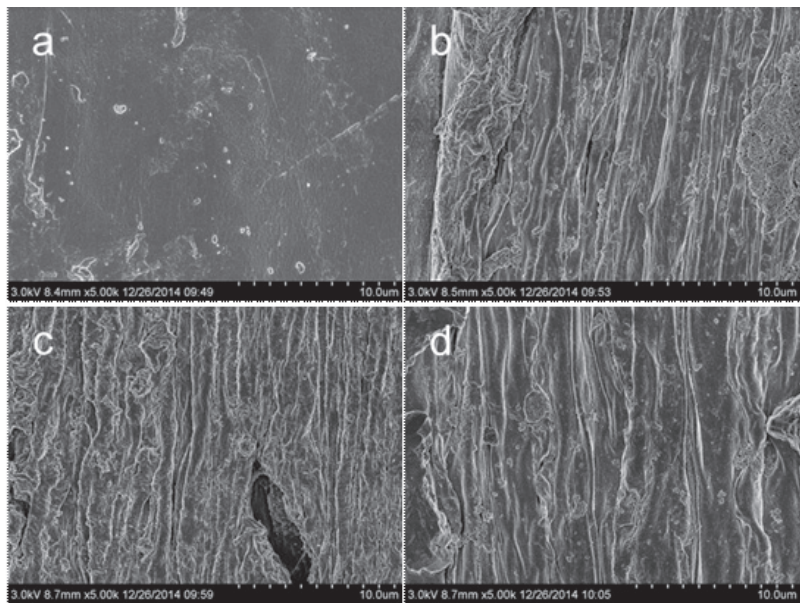

Fig. 2. Comparison of the SEM images of raw wheat straw a) and the pretreated wheat straw by $4 \%, 6 \%, 8 \% \mathrm{NaOH}$ for 8 days $(\mathrm{b}$, c, d), respectively. pretreatment [14]. There are some notable differences in bands at $1,610 \mathrm{~cm}^{-1}$ and $1,510 \mathrm{~cm}^{-1}$, which are characteristic bands of the aromatic ring of lignin, suggesting that the structure of lignin changed. This result is consistent with the composition analysis and SEM observation. After pretreatment, the transmittance

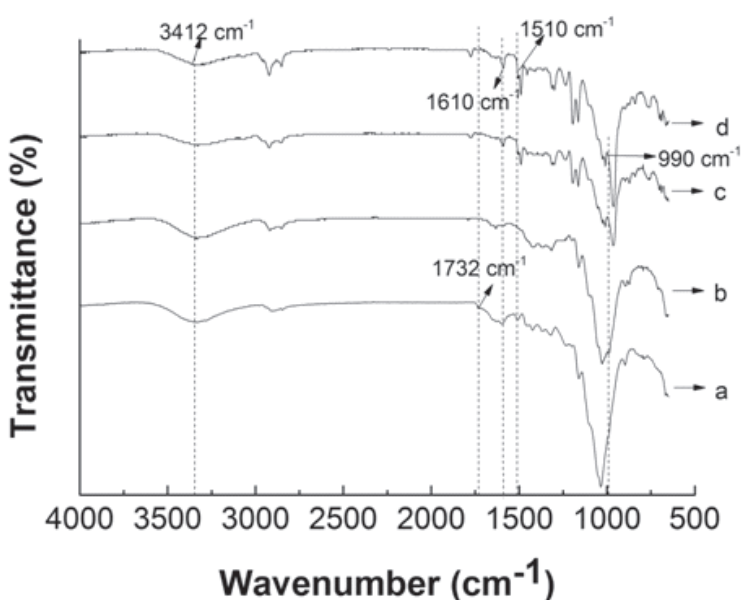

Fig. 3. Comparison of the FT-IR spectra of raw wheat straw a) and the pretreated wheat straw by $4 \%, 6 \%, 8 \% \mathrm{NaOH}$ for 8 days (b, c, d), respectively. 


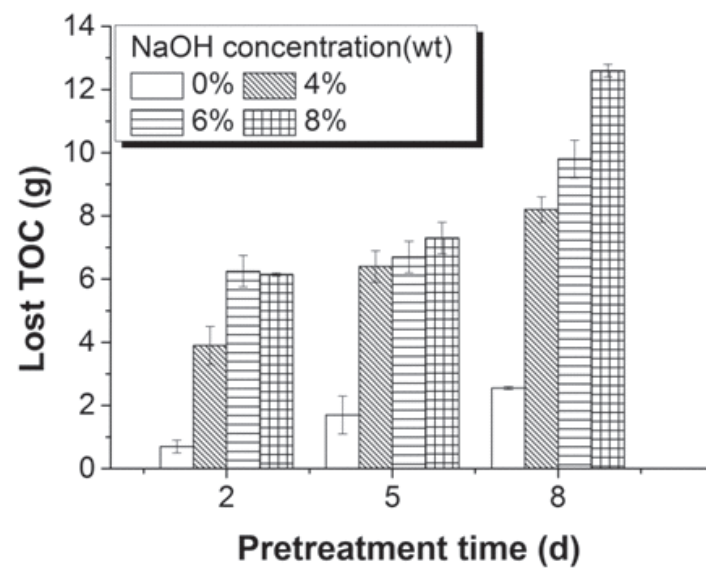

Fig. 4. Lost $\mathrm{TOC}$ in $\mathrm{NaOH}$ pretreatment. Y-axis means the lost TOC comparing with the mass of substrate, $\mathrm{g} / 65 \mathrm{~g}$.
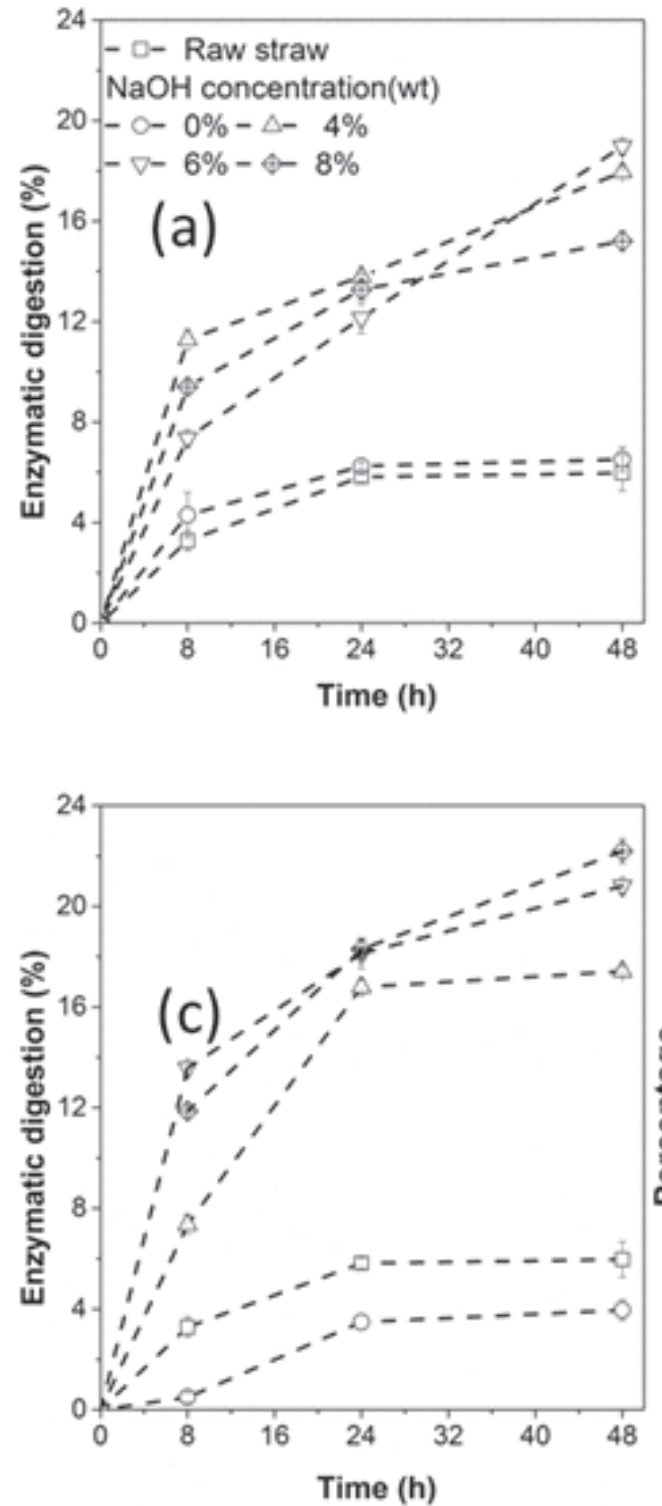

of bands, like $3,412 \mathrm{~cm}^{-1}$ (H-bonded $\mathrm{O}-\mathrm{H}$ stretching) and $990 \mathrm{~cm}^{-1}(\mathrm{C}-\mathrm{H}$ deformation) have some increase because the content of these groups in substrate increased, reflecting the depolymerization of lignocellulose polymers and disruption of the crystalline structure [28-29].

\section{Loss of Total Organic Carbon During Pretreatment}

The changes of TOC at different $\mathrm{NaOH}$ concentrations and different pretreatment times are presented in Fig. 4.

It is clear that both purified water and $\mathrm{NaOH}$ pretreatment caused TOC loss. Seven-hundred milligrams of TOC (based on $65 \mathrm{~g}$ substrate) were lost after two days pretreated by purified water and no more than $3 \mathrm{~g}$ TOC
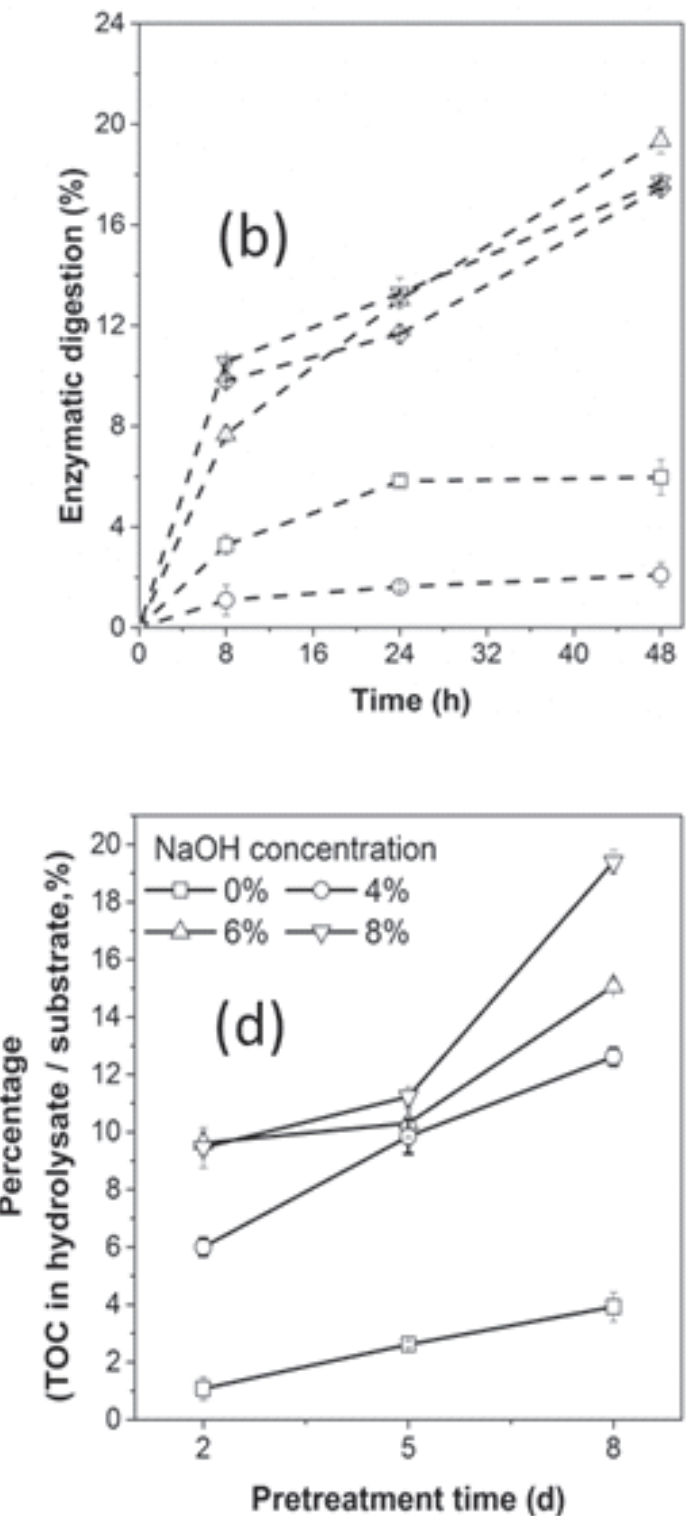

Fig. 5. Enzymatic digestion of wheat straw and loss ratio of TOC. Samples for enzymatic hydrolysis were taken after 2 a), 5 b) and 8 days c), Y-axis means percentage that the outcome of enzymatic hydrolysis to total mass; the legend in a) applies to b) and c). The lost TOC ratios were also described d). 
were lost after eight days. This lost TOC might be from some low-weight matter, like organic acid. Compared with pure water pretreatment, the content of TOC in $\mathrm{NaOH}$ pretreatment liquid substantially increased. The lost TOC was $4 \mathrm{~g}$ after two days pretreatment by $4 \%$ $\mathrm{NaOH}$, and doubled after eight days. During the first five days, $6 \%$ and $8 \% \mathrm{NaOH}$ pretreatment caused a close and stable loss, which was about 6 to $7 \mathrm{~g}$, but the TOC loss had a sharp increase after eight days. It was also found that after eight days, the TOC loss was $8 \mathrm{~g}$ from the wheat straw pretreated by $4 \% \mathrm{NaOH}$ while increasing to $13 \mathrm{~g}$ when pretreated by $8 \% \mathrm{NaOH}$. The results indicate that the $\mathrm{NaOH}$ concentration and pretreatment time had great effects on wheat straw.

\section{Comparison of Enzymatic Digestion and Loss Ratio of TOC}

Enzymatic digestion experiments were carried out for $48 \mathrm{~h}$ at $45^{\circ} \mathrm{C}$, which is regarded as optimal [30]. The results are shown in Figs 5a-5c.

The enzymatic digestion of substrates pretreated by purified water and raw material had very low hydrolysis, which remained at around $4 \%$ after $48 \mathrm{~h}$. The enzyme attacked the target with difficultly because most hemicellulose and cellulose were covered by lignin. However, after pretreatment enzymatic digestion appeared to increase distinctly. The maximal enzymatic digestion of the substrates taken after two and five days was $19.7 \%$ with $6 \% \mathrm{NaOH}$ and $19.5 \%$ with $4 \% \mathrm{NaOH}$, respectively (Figs 5a-5b). After pretreatment for eight days, $8 \% \mathrm{NaOH}$ resulted in a maximum of $22 \%$ enzymatic digestion for $48 \mathrm{~h}$ and the percentage would continue to rise (Fig. 5c). This led us to assume that $8 \% \mathrm{NaOH}$ pretreatment at $35^{\circ} \mathrm{C}$ could generate the largest enzymatic yield in enough enzymatic time.

However, even though $\mathrm{NaOH}$ pretreatment resulted in prime enzymatic digestion, unexpected loss of TOC (Eq. 5) was aggravated in long-term pretreatment with such alkali concentrations (Figure 5d). After two days of pretreatment, the most serious loss ratio of TOC was 10\%, while this value reached $20 \%$ after eight days with $8 \%$ $\mathrm{NaOH}$ pretreatment. The lost organic matters were some low-weight molecules that could easily be converted into biofuel by fermentation. Therefore, it is not economic and causes a huge waste of carbon resource if organic matter is lost in pretreatment. Unfortunately, the loss of organic matter in the pretreatment process is not given as much importance. It is worth thinking about how to control the balance between the loss of TOC and enhancement of hydrolysis.

\section{Conclusion}

$\mathrm{NaOH}$ pretreatment can change the composition and structure of wheat straw, even at a mesophilic temperature. The lignin has been removed effectively after $\mathrm{NaOH}$ pretreatment. Compared with purified water pretreatment and non-pretreatment, $\mathrm{NaOH}$ pretreatment exhibits good performance on enhancing enzymatic hydrolysis. But at the same time, a large ratio of TOC loss is caused. So the pretreatment conditions should be carefully chosen to ensure the treatment effect while reducing organic loss. The evaluation criteria of a pretreatment method should be included with comprehensive factors such as TOC loss, hydrolytic yield, process complexity, treatment cost, environmental friendliness, etc.

\section{Acknowledgements}

This study was supported by the National High Technology Research and Development Program of China (2012AA063507), the National Natural Science Foundation of China (21406263), and the Science Foundation of China University of Petroleum, Beijing (2462015YQ1303).

\section{References}

1. ALONSO, BOND, DUMESIC. Catalytic conversion of biomass to biofuels. Green Chem. 12 (9), 1493, 2010.

2. KARUNANITHY, MUTHUKUMARAPPAN. Optimization of alkali soaking and extrusion pretreatment of prairie cord grass for maximum sugar recovery by enzymatic hydrolysis. Biochem. Eng. J. 54 (2), 71, 2011.

3. JIANG, ZHUANG, FU, HUANG, WEN. Bioenergy potential from crop residues in China: Availability and distribution. Renewable and Sustainable Energy Reviews. 16 (3), 1377, 2012.

4. ZHU, HUANG, HUANG, WANG, CHEN, WU. Coproduction of xylose, lignosulfonate and ethanol from wheat straw. Bioresour. Technol. 185, 234, 2015.

5. CURRELI, AGELLI, PISU, RESCIGNO, SANJUST, RINALDI. Complete and efficient enzymic hydrolysis of pretreated wheat straw. Process Biochem. 37 (9), 937, 2002.

6. CARLSSON, LAGERKVIST, MORGAN-SAGASTUME. The effects of substrate pre-treatment on anaerobic digestion systems: A review. Waste Manage. (Oxford). 32 (9), 1634, 2012.

7. LI, NG, PUAH, BHASKAR, SOH, MACBEATH, PARAKATTIL, GREEN, WU. Efficient production of fermentable sugars from oil palm empty fruit bunch by combined use of acid and whole cell culture-catalyzed hydrolyses. Biotechnol. Appl. Biochem. 61 (4), 426, 2014.

8. XU, CHENG, SHARMA-SHIVAPPA, BURNS. Sodium Hydroxide Pretreatment of Switchgrass for Ethanol Production. Energy Fuels. 24 (3), 2113, 2010.

9. KATARIA, GHOSH. NaOH Pretreatment and Enzymatic Hydrolysis of Saccharum spontaneum for Reducing Sugars Production. Energy Sources, Part A: Recovery, Utilization, and Environmental Effects. 36 (9), 1028, 2014.

10. CARRILLO, LIS, COLOM, LÓPEZ-MESAS, VALLDEPERAS. Effect of alkali pretreatment on cellulase hydrolysis of wheat straw: Kinetic study. Process Biochem. 40 (10), 3360, 2005.

11. TAHERDANAK, ZILOUEI. Improving biogas production from wheat plant using alkaline pretreatment. Fuel. 115, 714, 2014.

12. LUCY F.R. Montgomery, Pretreatment of feedstock for 
enhanced biogas production, IEA Bioenergy, 2014.

13. ASGHAR, IRFAN, IRAM, HUMA, NELOFER, NADEEM, SYED. Effect of alkaline pretreatment on delignification of wheat straw. Nat. Prod. Res. 29 (2), 125, 2015.

14. TALEBNIA, KARAKASHEV, ANGELIDAKI. Production of bioethanol from wheat straw: An overview on pretreatment, hydrolysis and fermentation. Bioresour. Technol. 101 (13), 4744, 2010.

15. VAVILIN, FERNANDEZ, PALATSI, FLOTATS. Hydrolysis kinetics in anaerobic degradation of particulate organic material: an overview. Waste Manage. (Oxford). 28 (6), 939, 2008.

16. BALAT. Production of bioethanol from lignocellulosic materials via the biochemical pathway: A review. Energy Convers. Manage. 52 (2), 858, 2011.

17. STROOT, MCMAHON, MACKIE, RASKIN. Anaerobic codigestion of municipal solid waste and biosolids under various mixing conditions - I. digester performance. Water Res. 35 (7), 1804, 2001.

18. WEILAND. Biogas production: current state and perspectives. Appl. Microbiol. Biotechnol. 85, 849, 2010.

19. CHANG, TU, HUANG, LAY, LIN. Hydrogen production by the anaerobic fermentation from acid hydrolyzed rice straw hydrolysate. Int. J. Hydrogen Energy. 36 (21), 14280, 2011.

20. HIDENO, INOUE, YANAGIDA, TSUKAHARA, ENDO, SAWAYAMA. Combination of hot compressed water treatment and wet disk milling for high sugar recovery yield in enzymatic hydrolysis of rice straw. Bioresour. Technol. 104, 743, 2012.

21. SILVA, COUTURIER, BERRIN, BULEON, ROUAU. Effects of grinding processes on enzymatic degradation of wheat straw. Bioresour. Technol. 103 (1), 192, 2012.

22. APHA, Standard Methods for the Examination of Water and Wastewater, American Public Health Association, Washington, DC, 1998.

23. ANKOM Technology:Method for determining acid detergent lignin in beakers; method for determining acid detergent fiber; method for determining neutral detergent fiber., in ANKOM Technology, https://ankom.com/ analytical-methods-support/fiber-analyzer-a200, pp. Method for determining acid detergent lignin in beakers; method for determining acid detergent fiber; method for determining neutral detergent fiber. .

24. Hach, Total Organic Carbon (TOC) Reagent Set, LR, in, Hach Company, http://www.hach.com/total-organic-carbontoc-reagent-set-lr/product-parameter-reagent?id=764019684 $7 \&$ callback=qs, pp. Direct method for TOC.

25. HANSEN, AHL, PEDERSEN, WESTERENG, WILLATS, JØRGENSEN, FELBY. Extractability and digestibility of plant cell wall polysaccharides during hydrothermal and enzymatic degradation of wheat straw. Industrial Crops and Products. 55, 63, 2014.

26. DE LA RUBIA, FERNÁNDEZ-CEGRÍ, RAPOSO, BORJA. Influence of particle size and chemical composition on the performance and kinetics of anaerobic digestion process of sunflower oil cake in batch mode. Biochem. Eng. J. 58-59, 162, 2011.

27. LIANG, CHENG, SI, CAO, NIE, TANG, LIU, ZHENG, LUO. Physicochemical changes of rice straw after lime pretreatment and mesophilic dry digestion. Biomass Bioenergy. 71, 106, 2014.

28. LAUREANO-PEREZ, TEYMOURI, ALIZADEH, DALE, Understanding Factors that Limit Enzymatic Hydrolysis of Biomass, in: Davison, Evans, Finkelstein, Mcmillan (Eds.) Twenty-Sixth Symposium on Biotechnology for Fuels and Chemicals, Humana Press, 81, 2005.

29. SUGIYAMA, PERSSON, CHANZY. Combined infrared and electron diffraction study of the polymorphism of native celluloses. Macromolecules. 24 (9), 2461, 1991.

30. DA SILVA, INOUE, ENDO, YANO, BON. Milling pretreatment of sugarcane bagasse and straw for enzymatic hydrolysis and ethanol fermentation. Bioresour. Technol. 101 (19), 7402, 2010. 